\title{
A Química \\ e os cerâmicos tradicionais
}

\section{Introdução}

Escrever sobre a interacção entre a química e a cerâmica é praticamente falar sobre todo o processo cerâmico, pelo que a abordagem se reveste de alguma dificuldade se o objectivo consiste em sintetizar o que de mais importante uma ciência traz à outra.

A opção que fizemos, foi, então, a de começar pela apresentação de um esquema geral de fabrico dos cerâmicos a que se seguirá uma resenha das principais reacções químicas em cada um dos processos abordados. Pode dizer-se que, de uma forma geral, o objectivo do processamento cerâmico consiste em fabricar objectos com propriedades bem determinadas a partir de pós naturais ou sintéticos, por um método que passa da conformação à consolidação com intervenção de temperaturas mais ou menos elevadas em alguma fase. No caso dos cerâmicos tradicionais, isto é, das telhas e tijolos, dos azulejos e mosaicos, da louça artística e doméstica, dos refractários silico-aluminosos, o processo de fabrico pode ser esquematizado da seguinte forma:

1. Preparação de pasta - aqui se procede à moagem e mistura dos componentes da pasta de forma a obter um conjunto de granulometria reduzida e homogéneo em termos macroscópicos que passa à fase seguinte.

2. Conformação - obtenção dos objectos com a forma pretendida.

3. Secagem - em todos os processos de conformação se verifica a presença de água entre os constituintes da pasta, pelo que se torna necessário proceder à sua eliminação antes da

4. Primeira Cozedura - procedendo-se à primeira cozedura a temperaturas diversas, entre 850 e $1250^{\circ} \mathrm{C}$, de acordo com o tipo de pasta com que se trabalha, o objectivo é sempre o de consolidar o material, o que neste caso acontece pelo aparecimento de uma fase líquida que liga as partículas entre si.

5. Vidragem - operação que se destina a recobrir as peças de uma camada de pó de composição tal que funda durante a fase seguinte do processo impermeabilizando as peças. A decoração é muitas vezes realizada no mesmo processo.

6. Cozedura de vidrado - nesta se levam as peças a temperaturas que variam entre 950 e $1450^{\circ} \mathrm{C}$ para que o vidrado aplicado na etapa anterior funda e adira à peça, constituindo com ela um corpo único.

\%. Escolha e embalagem - esta operação destina-se naturalmente a separar as peças defeituosas e impedir que elas cheguem ao consumidor.

Este esquema global pode sofrer algumas alteraçðes. Assim, as telhas e os tijolos têm, geralmente, uma cozedura única, após o que se encontram em condiçðes de escolha e embalagem. Determinadas peças, particu- larmente na área dos pavimentos e revestimentos, não são submetidas a cozedura antes da vidragem, realizando-se a consolidação da peça e do vidrado em simultâneo, num processo que se designa por monocozedura. Se pretendêssemos abordar o processamento dos cerâmicos com utilização técnica, sejam os que se destinam à electrónica ou os que desempenham papéis estruturais, encontraríamos diferenças que se traduzem particularmente na inexistência de vidragem e na possibilidade de a conformação e a cozedura terem lugar simultaneamente num processo como a prensagem a quente, em que o objecto é conformado por prensagem a temperatura elevada que permite a sua consolidação. Os cimentos constituem um caso particular dos cerâmicos, na medida.em que a conformação se realiza apenas após o processo de cozedura que, neste caso, recebe o nome de clinquerização.

Feita esta pequena introdução à cerâmica, vejamos como intervém a química ao longo das diferentes etapas de fabrico.

\section{Preparação de pasta}

Como introdução à preparação de pasta, refira-se que as matérias-primas comuns em cerâmicos tradicionais são argilas e caulinos, areia, feldspato ou calcite e dolomite e, ainda, peças defeituosas moidas, que se designam por caco.

A preparação de pasta pode ser realizada por tês vias distintas: seca, plástica, húmida. Na primeira e na segunda os materiais são moídos a seco ou com a mistura de uma pequena quantidade de água, na segunda com a formação de suspensðes aquosas. Aqui, cabe à quimica, com especial relevo para a quimica coloidal, um papel importante. Por dois motivos, a saber: a reGução do tamanho das partículas resulta num aumento da sua área especifica, isto é, da área por unidade de massa, que se traduz em incremento da energia superficial. Numa tentativa para reduzir a sua energia total, o sistema reage procurando agregar as partículas mais pequenas, contrariando assim o objectivo da moagem. Por outro lado, as partículas dos minerais das argilas apresentam, em suspensðes aquosas, carga eléctrica dissemelhante nas suas superfícies, de que pode resultar o estabelecimento de ligaçðes.

Em qualquer dos casos é, portanto, necessário actuar de forma a diminuir ou eliminar a tendência das particulas para a agregação. Como actua um químico nestas circunstâncias? Aumentando a repulsão entre as particulas. Para o efeito, adiciona à suspensão compostos que modifiquem a interface partícula-água. a Departamento de Engenharia Cerâmica e do Vidro, Universidade
de Aveiro. 
Vejamos como actuam.

Se procedermos à dissolução de bases, o aumento de $\mathrm{pH}$ resultante vai permitir eliminar a dissemelhança electrostática das partículas dos minerais argilosos, que adquirem cargas negativas em todas as suas superfícies. Caso a força iónica do meio suspensor seja reduzida, o que não é, no entanto, sempre o caso, a repulsão que se estabelece entre as partículas pode ser suficiente para impedir a sua agregação.

Efeito semelhante, mas mais pronunciado, se consegue pela adição de aniðes como o silicato e o fosfato. A facilidade com que qualquer das duas espécies adsorve na superfície das partículas dos minerais argilosos, com especial relevância para o último que parece formar complexos com os átomos que nelas se encontram, permite aumentar eficazmente a carga global negativa das particulas e impedir que se agreguem.

Alguns polímeros e polielectrólitos aniónicos são utilizados com o mesmo fim. Se, nos últimos, parte do efeito conseguido se deve â um mecanismo semelhante ao apresentado para o efeito da adsorção dos aniōes e do aumento de $\mathrm{pH}-$ aparecimento de uma carga negativa elevada em todas as superfícies, com estabelecimento de forte repulsão electrostática entre elas - existe ainda uma contribuição estérea também presente quando se lida com polímeros não iónicos. Esta pode ser compreendida através do recurso a noçð̄es simples de termodinâmica, aliadas ao conhecimento da configuração adoptada por espécies poliméricas quando adsorvem em superfícies sólidas a partir de soluçðеs.

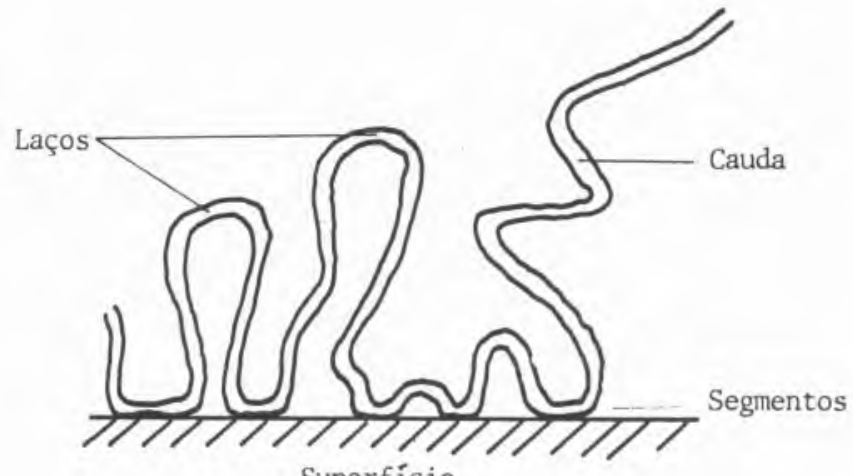

Superfície

Fig. 1

Conformação de um polimero adsorvido numa superficie

Um polimero ou polielectrólito em solução num solvente melhor que um solvente teta adquire, por adsorção em superfícies sólidas, a configuração que se representa na Figura 1, ligando-se à superfície por alguns dos pontos da sua cadeia enquanto deixa em solução laços e caudas. Quando duas partículas com polímeros adsorvidos se aproximam, ocorrem dois factos: as cadeias interaccionam entre si, substituindo as ligaçðes polimero-solvente por ligaçðes polímero-polímero e, para menores distâncias de interacção, interpenetram-se. Do primeiro resulta, em solventes melhores que teta, um aumento da entalpia do sistema e do segundo uma diminuição da sua entropia, por diminuição do número de configuraçð̄es possíveis para cada molécula adsorvida. Desta forma, e atendendo a que

$$
\Delta \mathrm{G}=\Delta \mathrm{H}-\mathrm{T} \Delta \mathrm{S}
$$

a aproximação de partículas com cadeias poliméricas adsorvidas quando suspensas num meio melhor que um solvente $\theta$ resulta num aumento da energia livre do sistema, pelo que é desfavorecida. As partículas mantêm-se, por isso, afastadas.

A separação das partículas não pode, no entanto, ser completa no processo de preparação de pasta, porque, continuando a trabalhar-se com suspensðes no processo de fabrico, dai resultaria a possibilidade de nos tanques de depósito se verificar a separação da pasta por ordem de granulometria, o que obriga a um compromisso entre a necessidade de contrariar a agregação das partículas para que se obtenha uma pasta fina e uma outra que é de contrariar a separação granulométrica que ocorreria numa suspensão em que as partículas se encontrassem completamente separadas e a agitação não fosse muito vigorosa.

Aliás, a fase final da preparação de pasta consiste, geralmente, numa pré-secagem que permita a continuação do processo de fabrico. Esta operação é feita em atomizadores quando se pretende obter um pó com cerca de $5 \%$ de humidade que será prensado, ou filtros-prensa, quando a conformação é realizada plasticamente. Ora, neste caso, a completa separação das partículas traduzir-se-ía no entupimento das telas utilizadas para separar a água da pasta e, portanto, numa quebra de rendimento do processo.

Em conclusão, na preparação de pasta de cerâmicos tradicionais por via húmida utilizam-se soluçð̄es de compostos monoméricos ou poliméricos, com ou sem carga, que adsorvem nas superfícies das partículas em suspensão impedindo, parcialmente, a sua agregação e favorecendo, portanto, a diminuição do seu tamanho.

\section{Conformação}

Os processos de conformação dos cerâmicos tradicionais podem ocorrer por via semi-seca, plástica e por via húmida. No primeiro não se utilizam, geralmente, aditivos químicos. No segundo e no terceiro torna-se necessário controlar a plasticidade ou a viscosidade do sistema, pelo que a química volta a estar presente. Assim, quando se procede à extrusão de um tijolo ou à extrusão seguida de prensagem de uma telha, necessário se torna garantir a plasticidade da pasta adequada a um processo de que não resultem defeitos. A presença de iðes multivalentes adsorvidos na superfície das partículas dos minerais argilosos, como compensação das suas cargas intrínsecas, permite melhorar a plasticidade da pasta, uma vez que as camadas de hidratação dos iðes actuam como camada lubrificante entre as partículas no movimento relativo que executam por acção da extrusora ou da prensa.

No caso da conformação por via húmida, que se utiliza, por exemplo, nos sanitários, a água de suspensão argilosa é retirada por moldes porosos de gesso. A velocidade a que este processo decorre e as características das paredes formadas dependem da existência ou não de ligaçðes entre as partículas. Quando elas se verificam, formam-se agregados muito porosos que deixam passar a água com muita facilidade - demasiada, mesmo - para os moldes, mas originam paredes pouco densas e facilmente deformáveis. Quando as particulas se encontram individualizadas, as paredes são pouco porosas, de permeabilidade reduzida, atrasando o processo e originando objectos frágeis.

O compromisso entre estas duas situaçðes é conseguido actuando sobre a carga das partículas dos minerais ar- 
gilosos, como se fizera na preparação de pasta, se bem que com acrescido rigor, resultante da necessidade de obtenção de objectos de características bem definidas e constantes.

\section{Secagem}

Após a conformação procede-se à secagem das peças de forma a poder levá-las posteriormente ao forno. O processo em si não seria referido aqui se não fosse pelo aparecimento, no seu final, de um defeito sobre o qual os químicos, uma vez mais, devem actuar - as eflorescências, pós finos que aparecem à superfície das peças como resultado da existência de sais solúveis na água ou nas matérias-primas. A sua eliminação deverá passar pela substituição do ingrediente que lhe deu origem, o que não é, no entanto, sempre possivel. Os sais solúveis são, na maior parte dos casos, sulfatos, pelo que a resolução do problema envolve, geralmente, a adição de carbonato de bário, sal pouco solúvel, à suspensão original ou à água, para que precipitem o sulfato deste elemento e o carbonato do catião constituinte do sal.

\section{Cozedura}

É esta, sem dúvida, a etapa do processo de fabricação dos cerâmicos durante a qual têm lugar as mais importantes transformaçð̄es químicas. Separemo-las em dois tipos fundamentais: decomposição de compostos inicialmente presentes e formação de novos compostos.

\subsection{Decomposição}

A decomposição de compostos presentes nas matéria-primas inicia-se a cerca de $200{ }^{\circ} \mathrm{C}$, com a desidroxilação dos hidróxidos presentes, nomeadamente de ferro, que se processa com libertação de vapor de água.

A temperaturas ligeiramente superiores, estendendo-se no intervalo de 300 a $800{ }^{\circ} \mathrm{C}$, dá-se a combustão da matéria orgânica muitas vezes encontrada nas argilas, resultante da decomposição de árvores e arbustos presentes no local de formação daquelas matérias-primas. A combustão é acompanhada da libertação de vapor de água e de dióxido de carbono.

Entretanto, no intervalo de temperaturas de 450 a 600 ${ }^{\circ} \mathrm{C}$, dependendo da sua natureza e da sua cristalinidade, ocorre a decomposição dos minerais das argilas que, perdendo, sob a forma de água, os iðes hidroxilo que faziam parte da sua rede cristalina, perdem irreversivelmente a sua plasticidade característica. A caulinite, muito comum nos caulinos, origina desta forma o metacaulino.

Os carbonatos de cálcio e duplo de cálcio e magnésio presentes na calcite e na dolomite, respectivamente, decompðem-se a temperaturas entre 800 e $900{ }^{\circ} \mathrm{C}$, originando dióxido de carbono e os respectivos óxidos metálicos. Os feldspatos, também utilizados como fundentes, decompðem-se a temperaturas mais elevadas, da ordem dos $1100{ }^{\circ} \mathrm{C}$, originando um vidro. No entanto, o feldspato potássico dá, ainda, lugar a leucite, que desaparece apenas a cerca de $1500^{\circ} \mathrm{C}$, o que permite explicar a maior viscosidade que os feldspatos potássicos apresentam a uma dada temperatura em comparação com os sódicos.

\subsection{Formação de novos compostos}

A decomposição dos compostos inicialmente presentes nas matérias-primas origina substâncias com elevada área específica superficial, logo, reactivas. Assim, na continuação do processo de cozedura são criadas as condiçðes para a formação de novos compostos.

$\mathrm{O}$ óxido de cálcio libertado durante a decomposição do carbonato de cálcio reage com a sílica presente para originar silicatos com incorporação crescente do metal por elevação da temperatura. A presença de alumina resultante de decomposição de aluminosilicatos permite a formação de aluminatos de cálcio.

$\mathrm{O}$ metacaulino resultante da desidroxilação da caulinite origina, a cerca de $950{ }^{\circ} \mathrm{C}$, uma espinela que, a temperaturas superiores, se decompõe numa mal cristalizada mulite e cristobalite.

A cerca de $1100{ }^{\circ} \mathrm{C}$, a presença de feldspatos leva à formação de um vidro que rodeia os grãos e participa nas reacçōes subsequentes como meio de transporte das espécies envolvidas, particularmente na formação e crescimento de cristais de mulite e, ainda, na dissolução da sílica cuja incorporação no vidro aumenta com a temperatura.

Enquanto estas reacçōes se processam, dá-se a diminuição do tamanho da peça e da sua porosidade, como consequência da tendência do sistema e diminuir a sua área específica. Ocorre, então, o que de designa por densificação. Obtido o grau de consolidação pretendido, que varia com o tipo de material, procede-se ao arrefecimento das peças até à temperatura ambiente, que não é, geralmente, acompanhado por alteraçōes químicas.

$\mathrm{Na}$ grande maioria dos casos, particularmente quando se utiliza cozedura rápida, todos os processos de que falámos ocorrem sem que se atinja o estado de equilíbrio. São factores cinéticos que determinam a extensão relativa das reacçðes e que determinam em boa medida os produtos que se formam. Não admira, portanto, que o estudo da cinética de reacçōes envolvendo constituintes das pastas argilosas e dos cimentos tenha tido um tão grande desenvolvimento. Os problemas de equilíbrio poem-se quer em processos de cozedura muito prolongados quer ainda durante a utilização dos produtos. E este último o caso dos materiais refractários utilizados nos fornos cerâmicos. Submetidos às mesmas condiçőes de temperatura e ambientais anos seguidos, os estudos que lhes são dedicados são fundamentalmente de equilibrio, sendo publicadas anualmente novas alteraçðes aos seus diagramas de fases.

\subsection{Detecção das reacções}

O conhecimento das reacçðes que se passam durante o processo de cozedura de um cerâmico é importante para que se possam tomar medidas necessárias a evitar efeitos não pretendidos, como a quebra de uma peça por aquecimento demasiado rápido na zona de decomposição dos minerais de argila. Com este sentido se utilizam duas técnicas muito simples que permitem detectar a sua existência: a termogravimetria e a análise térmica diferencial. A termogravimetria ou análise termo-gravimétrica estuda a variação de peso de uma amostra em função da temperatura, permitindo estudar as reacçðes que para isso contribuem. A análise térmica diferencial permite, por comparação entre a temperatura da amostra e a temperatura de um inerte colocado a seu lado num forno, detectar a presença de fenómenos físicos ou químicos endotérmicos ou exotérmicos. Aplica-se, portanto, a um maior número de situaçōes que a técnica anterior. Nas Figuras 2 e 3 dão-se exemplos de curvas de análise térmica diferencial e gravimétrica de uma caulinite, onde se pode detectar a presença de algumas das reacçðes de que falámos. 


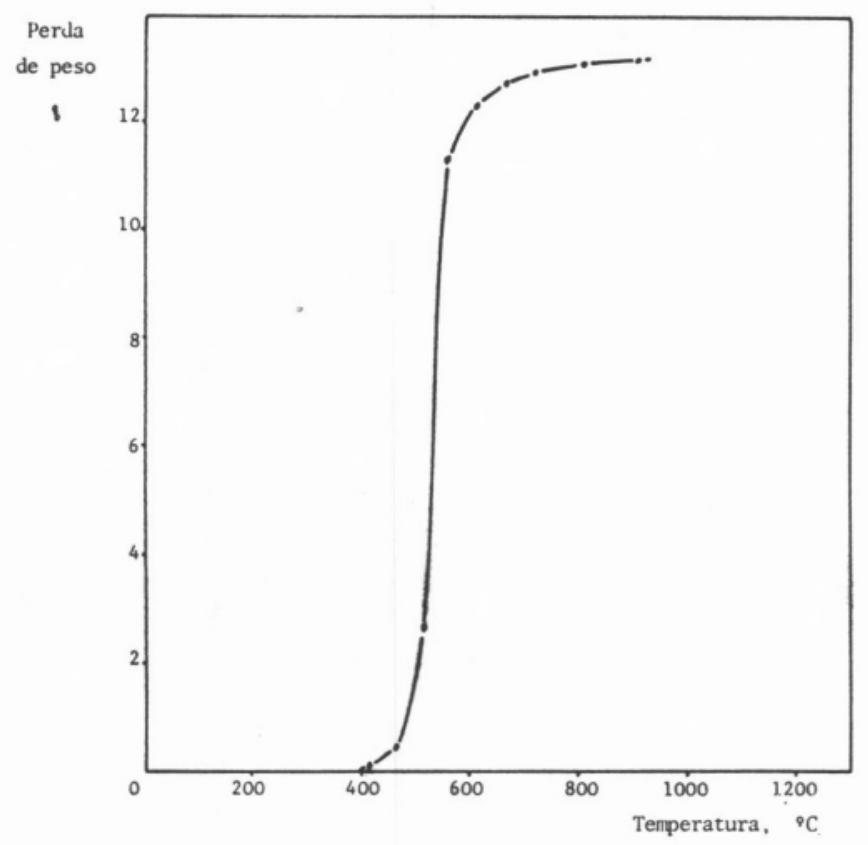

Fig. 2

Curva termogravimétrica de um caulino

\section{Processamento subsequente}

O processamento subsequente dos cerâmicos envolve a química de novo na aplicação e tratamento dos vidrados, na formação de cor, influência da composição e da atmosfera de cozedura. Este assunto será, no entanto, tratado em ocasião futura.

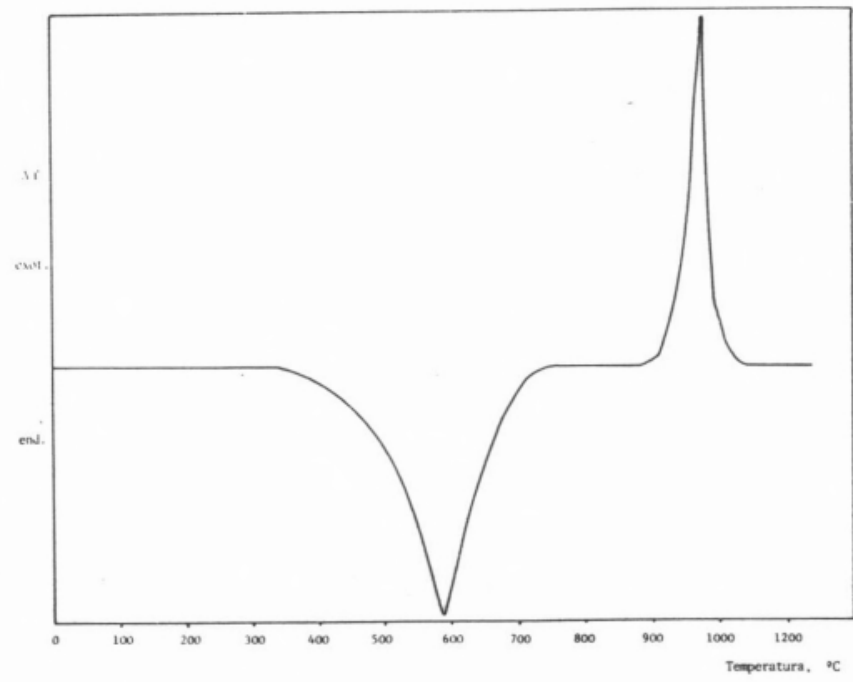

Fig. 3

Curva de análise térmica diferencial de um caulino

\section{Conclusão}

O processamento dos cerâmicos tradicionais necessita da compreensão de fenómenos químicos que vão da química coloidal e de superfícies às reacções no estado sólido e reacçð̄es na presença de fase líquida, dos estudos de cinética' aos problemas do equilíbrio. Só a sua compreensão permitirá desenvolver materiais com as propriedades requeridas nas condiçðes mais vantajosas. 

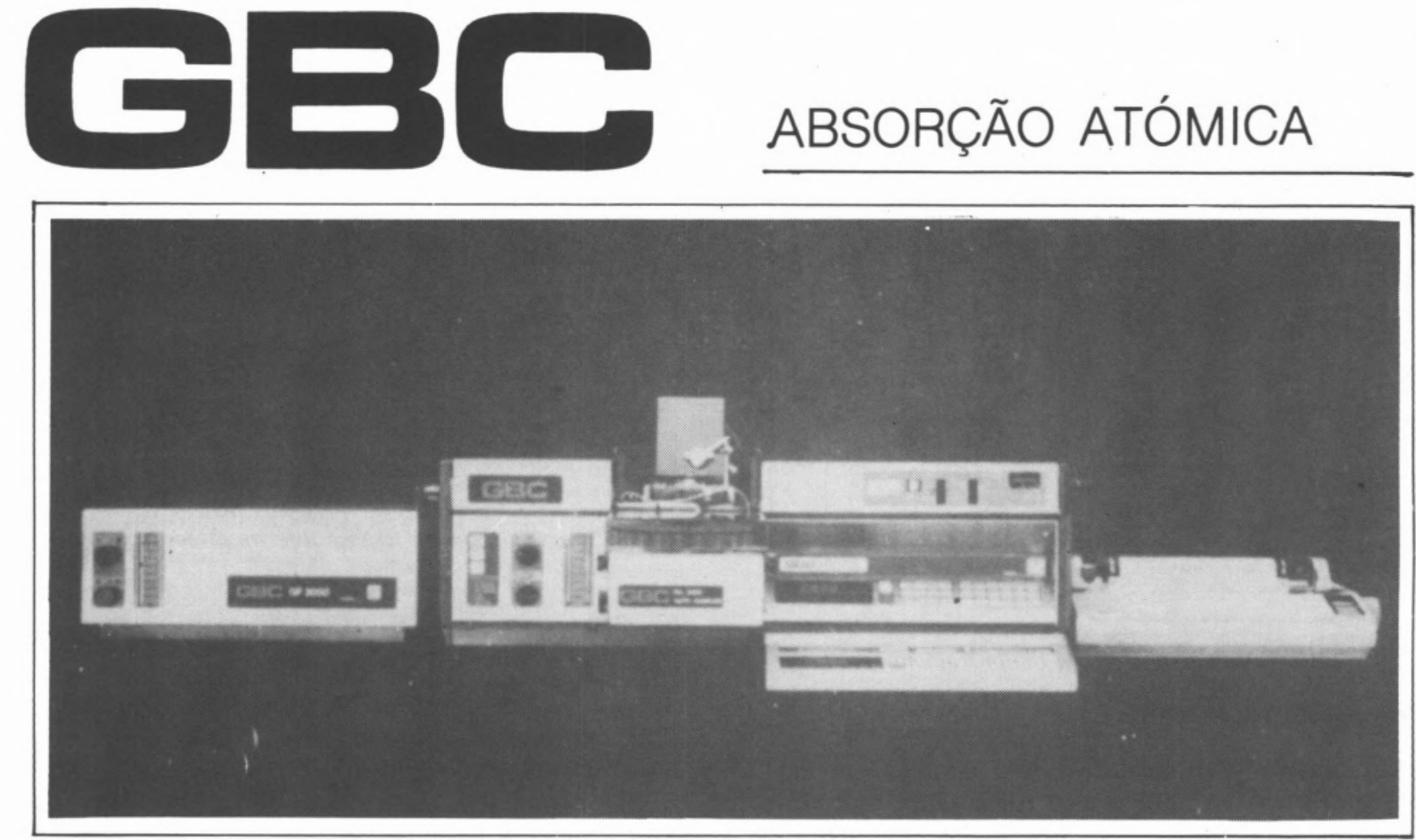

AGORA EM PORTUGAL ABSORÇÃO ATÓMICA CHAMA-SE:
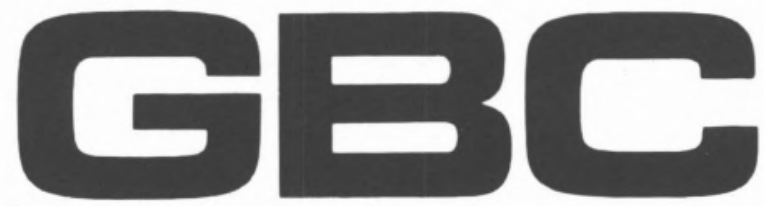

EXCELENTES EQUIPAMENTOS

AOS MELHORES PREÇOS DO MERCADO

(2 sistemas vendidos nos primeiros 3 meses de promoção)

PEÇA-NOS UMA OFERTA.

DISTRIBUIDORES EM PORTUGAL:
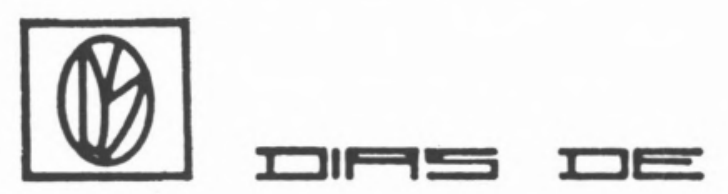

QUINTA DA PIEDADE, LOTE $12 \cdot 1 .{ }^{\circ} \mathrm{D}$. 2625 PÓVOA DE STA. IRIA

TEL. (01) $2592316 \cdot 2592409$

TLX. 43926 DISO P

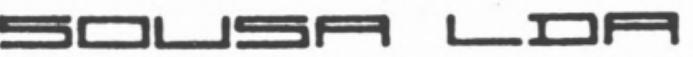

PRAÇA PEDRO NUNES, 94 4000 PORTO

TEL. (02) 931499 - 933809

TLX. 26250 NSC P 